\title{
Urinary Tract Stones Risk Factors in Patients with Benign Prostatic Hyperplasia in West Java, Indonesia
}

\author{
Iman Surendroputro Tjahjodjati, ${ }^{1}$ Bambang Sasongko Noegroho, ${ }^{2}$ Aaron Tigor Sihombing ${ }^{2}$
}

${ }^{1}$ Faculty of Medicine, Universitas Padjadjaran, Indonesia, ${ }^{2}$ Department of Urology Faculty of Medicine Universitas Padjadjaran/Dr. Hasan Sadikin General Hospital, Bandung, Indonesia,

\section{Abstract}

Background: Urinary tract stones are common in patients with benign prostatic hyperplasia (BPH); therefore, an imaging test is needed for patients who have risk factors for the formation of urinary tract stones. The purpose of this study was to explore the factors associated with the presence of urinary tract stones in patients with BPH as information to conduct imaging tests.

Methods: A cross-sectional quantitative analytic study was conducted on medical records of patients with $\mathrm{BPH}$, both with and without urinary tract stones, or patients with urinary tract stones registered at the Department of Urology, Dr. Hasan Sadikin General Hospital, Indonesia, from 2015 to 2018. Data on age, body mass index, hypertension, use of antihypertensive drugs, diabetes mellitus, and hyperuricemia were collected and analyzed using the Mann-Whitney, Chi-square, Fisher exact test, and multivariate logistic regression statistical test to compare variables between BPH with and without urinary tract stones.

Results: In total, $235 \mathrm{BPH}$ patients were registered, of whom 74 (31.5\%) had urinary tract stones. The median age was 64 years old. There was a relationship between age $(p=0.030)$, diabetes mellitus $(\mathrm{p}=0.043)$, and the occurrence of urinary tract stones in patients with BPH. The most dominant risk factor was diabetes mellitus (OR=3.000, 95\%CI 1.03-8.69).

Conclusions: Age and diabetes mellitus are the risk factors for urinary tract stones in patients with $\mathrm{BPH}$. BPH patients with diabetes mellitus are at a 3-fold risk for urinary tract stones. Diabetes mellitus in $\mathrm{BPH}$ patients is an indication to conduct imaging tests.

Keywords: Benign prostatic hyperplasia, diabetes mellitus, urinary tract stones

\section{Introduction}

Benign prostate hyperplasia (BPH) is one of the diseases often discovered in men aged 70-79 years by $80 \% 0^{1,2}$ In the course of the disease, BPH will become benign prostatic enlargement (BPE) that obstructs the lower urinary tract. ${ }^{3,4}$ This obstruction causes lower urinary tract symptoms (LUTS) and about $25-50 \%$ of individuals with BPH experience LUTS., 3

One of the complications of BPH is urinary tract stones, especially bladder stones. ${ }^{5}$ Benign prostatic hyperplasia is not the only risk factor related to the occurrence of urinary tract stones, but there are also intrinsic and extrinsic factors. ${ }^{6}$ The intrinsic factors consist of age, sex, race, heredity, metabolic disorders, systemic diseases, urinary tract infections, and anatomic abnormalities of the urinary tract, whereas the extrinsic factors consist of patterns of nutrition, climate, occupation, and education level. ${ }^{6,7}$

The symptoms of lower urinary tract stones in patients with BPH can be masked by symptoms of the BPH. The most frequent symptoms are hematuria $(37.1 \%)$ and urinary disorders (32.5\%). About $2.6 \%$ of patients with bladder stones have experienced symptoms of acute urinary retention that are probably caused by BPH or the stones themselves. Lower urinary tract stones in patients with BPH often go undetected because 15.5\% are asymptomatic and are only found on routine examinations. ${ }^{5}$ Imaging tests are not carried out regularly on patients with BPH in Indonesia. ${ }^{8}$ Imaging tests are only provided if the patients have hematuria, recurrent urinary tract infections, renal insufficiency, excessive urine residues, history of stones, and history

Correspondence: Iman Surendroputro Tjahjodjati, Faculty of Medicine Universitas Padjadjaran, Jalan Raya Bandung-Sumedang Km. 21, Jatinangor, Sumedang, West Java- Indonesia, E-mail: surendroputro@gmail.com 
of surgery on the urinary tract, ${ }^{8}$ leading to undiagnosed urinary tract stones. Therefore, the purpose of this study was to analyze other risk factors related to the presence of urinary tract stones in BPH patients as extra information to conduct the imaging tests.

\section{Methods}

A cross-sectional analytical study was carried out using secondary data from registries and medical records of patients with BPH with or without urinary tract stones in the Department of Urology Dr. Hasan Sadikin General Hospital Bandung, West Java, Indonesia. These patients were registered at the hospital from 2015 to 2018. This study was approved by the Research Ethics Committee of Universitas Padjadjaran Bandung number 749/UN6.KEP/ $\mathrm{EC} / 2019$. The BPH patients were grouped into group 1 that had BPH without urinary tract stones, and group 2 that had BPH with urinary tract stones. The inclusion criteria in this study were registries and medical records of BPH and urinary tract stones with BPH patients which contained data of age, blood pressure, body mass index (BMI), diabetes status, hyperuricemia status, and the use of antihypertensive drugs. Double registries/ medical records of the same patients were excluded. Age was divided into $\leq 59$ years, $60-$ 69 years, and $\geq 70$ years. Blood pressure was divided into no hypertension when systolic blood pressure was $\leq 139 \mathrm{mmHg}$ or diastolic blood pressure $\leq 89 \mathrm{mmHg}$ or the history of hypertension was not recorded, and having hypertension when systolic blood pressure $\geq 140 \mathrm{mmHg}$ or diastolic blood pressure $\geq 90$ mmHg or there was a history of hypertension. ${ }^{9}$ No obesity was designated when BMI $<23$ $\mathrm{kg} / \mathrm{m}^{2}$, and obesity if BMI $\geq 23 \mathrm{~kg} / \mathrm{m}^{2}{ }^{10}$ No diabetes mellitus (DM) was designated when fasting blood sugar level was $<126 \mathrm{mg} / \mathrm{dl}$ and DM when fasting blood sugar level was $\geq 126$ $\mathrm{mg} / \mathrm{dl}$. Not hyperuricemia when blood uric acid level was $\leq 6.8 \mathrm{mg} / \mathrm{dl}$ and hyperuricemia when blood uric acid level was $>6.8 \mathrm{mg} / \mathrm{dl}$. The use of antihypertensive drugs was recorded as using and not using antihypertensive drugs.

To test the distribution of the numerical data, the Kolmogorov-Smirnov test was carried out and when the result was not normally distributed, the bivariate statistical test used in this study was the non-parametric MannWhitney test. The Chi-square statistical test was used for analyzing hypertension, obesity, and the use of antihypertensive drugs while Fisher's exact test was used for analyzing the DM and hyperuricemia data. The logistic regression statistical test was used to analyze the most dominant factor for the occurrence of urinary tract stones in patients with BPH. The statistical analyses was performed using IBM SPSS Statistics Software, Version 25.0.

\section{Results}

In total, data on 235 patients with BPH were retrieved, of which $31.5 \%$ had urinary tract stones (Table 1). Moreover, most locations of urinary tract stones were in the lower urinary tract (47.3\%). Interestingly, the location of the stones would be both upper and lower urinary tract stones (32.4\%).

The median age of $\mathrm{BPH}$ patients was 68 years old, whereas the median age of BPH patients with urinary tract stones was 64 years old. The results showed that there was a relationship between age and the occurrence of urinary tract stones in $\mathrm{BPH}$ patients $(p=0.030)$. The BPH with urinary tract was mostly affected in patients aged 60-69 years (58.1\%). The increasing age was a risk for urinary tract stones in $\mathrm{BPH}$ patients $(\mathrm{p}=0.004)$.

Table 1 Distribution of BPH Patients Registered in the Dr. Hasan Sadikin General Hospital 2015-2018

\begin{tabular}{lcc}
\hline & $\begin{array}{c}\text { Frequency } \\
\text { (n) }\end{array}$ & $\begin{array}{c}\text { Percentage } \\
\text { (\%) }\end{array}$ \\
\hline BPH & 161 & 68.5 \\
BPH with urinary tract stones : & 74 & 31.5 \\
Upper urinary tract stones & 15 & 20.3 \\
Lower urinary tract stones & 35 & 47.3 \\
Upper and Lower urinary tract stones & 24 & 32.4 \\
Total & 235 & 100 \\
\hline
\end{tabular}

Note: $\mathrm{BPH}=$ Benign prostatic hyperplasia 
Table 2 Age as a Risk Factor for Urinary Tract Stones in BPH Patients

\begin{tabular}{|c|c|c|c|c|}
\hline \multirow[t]{2}{*}{ Risk Factor } & BPH & $\begin{array}{l}\text { BPH with } \\
\text { Urinary Tract } \\
\text { Stones }\end{array}$ & Total & \multirow[t]{2}{*}{ p-value } \\
\hline & $(n=161)$ & $(n=74)$ & $(n=235)$ & \\
\hline \multicolumn{5}{|l|}{ Age (n) } \\
\hline Median, years & 68 & 64 & & \multirow{3}{*}{$0.030^{*}$} \\
\hline Minimum, years & 48 & 48 & & \\
\hline Maximum, years & 97 & 86 & & \\
\hline$\leq 59$ years old $(\mathrm{n}, \%)$ & $30(18.6)$ & $13(17.6)$ & $43(18.3)$ & \multirow{3}{*}{$0.004^{* *}$} \\
\hline 60-69 years old $(n, \%)$ & $59(36.6)$ & $43(58.1)$ & $102(43.4)$ & \\
\hline$\geq 70$ years old $(\mathrm{n}, \%)$ & $72(44.7)$ & $18(24.3)$ & $90(38.3)$ & \\
\hline
\end{tabular}

Notes: ${ }^{*}$ Mann-Whitney statistical test, ${ }^{* *}$ Chi-Square statistical test

There were 5 risk factors for urinary tract stones in BPH patients that were tested statistically, which were hypertension, obesity, diabetes mellitus, hyperuricemia, and the use of antihypertension drugs as shown in Table 5. This study showed that there was a similar percentage between hypertensive and normotensive BPH patients experiencing urinary tract stones $(32.3 \%$ and $31.6 \%$, respectively). The result showed that there was no relationship between hypertension and urinary tract stones in $\mathrm{BPH}$ patients.

Obesity is one of the factors that contributed to the occurrence of urinary tract stones. This study had shown that $30.3 \%$ of obesity a patient with BPH had urinary tract stones. This percentage was lower compared to patients who were not obese. However, there was no relationship between obesity and the occurrence of urinary tract stones in $\mathrm{BPH}$ patients. Interestingly, the percentage of diabetes mellitus in $\mathrm{BPH}$ patients with urinary

Table 3 Other Risk Factors for Urinary Tract Stones in BPH Patients

\begin{tabular}{|c|c|c|c|c|}
\hline \multirow{2}{*}{ Risk Factor } & BPH & $\begin{array}{l}\text { Urinary Tract } \\
\text { Stones in BPH }\end{array}$ & Total & \multirow{2}{*}{ p-value } \\
\hline & $(n=161)$ & $(n=74)$ & $(n=235)$ & \\
\hline $\begin{array}{l}\text { Hypertension } \\
\text { No hypertension } \\
\text { Hypertension } \\
\text { Missing }\end{array}$ & $\begin{array}{l}52(68.4) \\
65(67.7)\end{array}$ & $\begin{array}{l}24(31.6) \\
31(32.3)\end{array}$ & $\begin{array}{l}76 \\
96 \\
63\end{array}$ & $0.921^{* *}$ \\
\hline $\begin{array}{l}\text { Obesity } \\
\quad \text { No obesity } \\
\text { Obesity } \\
\text { Missing }\end{array}$ & $\begin{array}{l}71(68.3) \\
46(69.7)\end{array}$ & $\begin{array}{l}33(31.7) \\
20(30.3)\end{array}$ & $\begin{array}{c}104 \\
66 \\
65\end{array}$ & $0.845^{* *}$ \\
\hline $\begin{array}{l}\text { Diabetes mellitus } \\
\quad \text { No diabetes mellitus } \\
\text { Diabetes mellitus } \\
\text { Missing }\end{array}$ & $\begin{array}{c}147(72.4) \\
7(46.7)\end{array}$ & $\begin{array}{c}56(27.6) \\
8(53.3)\end{array}$ & $\begin{array}{c}203 \\
15 \\
17\end{array}$ & $0.043^{* * *}$ \\
\hline $\begin{array}{l}\text { Hyperuricemia } \\
\text { No hyperuricemia } \\
\text { Hyperuricemia } \\
\text { Missing }\end{array}$ & $\begin{array}{c}9(28.1) \\
4(25)\end{array}$ & $\begin{array}{c}23(71.9) \\
12(75)\end{array}$ & $\begin{array}{c}32 \\
16 \\
187\end{array}$ & $1.000^{* * *}$ \\
\hline $\begin{array}{l}\text { The use of antihypertensive drugs } \\
\text { Negative } \\
\text { Positive } \\
\text { Missing }\end{array}$ & $\begin{array}{l}52(68.4) \\
65(67.7)\end{array}$ & $\begin{array}{l}24(31.6) \\
31(32.3)\end{array}$ & $\begin{array}{l}76 \\
96 \\
63\end{array}$ & $0.826^{* *}$ \\
\hline
\end{tabular}


Table 4 Antihypertension Drugs

\begin{tabular}{lccc}
\hline \multicolumn{1}{c}{ Antihypertension Drugs } & BPH & $\begin{array}{c}\text { Urinary Tract } \\
\text { Stones in BPH }\end{array}$ & Total \\
\cline { 2 - 4 } & $\mathbf{n ~ ( \% )}$ & $\mathbf{n ~ ( \% )}$ & $\mathbf{n = 1 0 2 *}$ \\
\hline Calcium-channel blocker & $34(69.4)$ & $15(30.6)$ & 49 \\
Angiotensin-converting enzyme inhibitor & $20(62.5)$ & $12(37.5)$ & 32 \\
Angiotensin receptor blocker & $5(62.5)$ & $3(37.5)$ & 8 \\
Diuretics & $5(71.4)$ & $2(28.6)$ & 7 \\
B-Blocker & $4(66.7)$ & $2(33.3)$ & 6 \\
\hline
\end{tabular}

Notes: * one patient could consume more than one type of antihypertension drug

tract stones was $53.3 \%$. This percentage was higher compared to patients without diabetes mellitus. There was a relationship between diabetes mellitus and urinary tract stones in BPH patients $(\mathrm{p}=0.043)$.

Hyperuricemia was found only in 16 of $48 \mathrm{BPH}$ patients. Of these, $12 \mathrm{BPH}$ patients were found with urinary tract stones and there was no relationship between hyperuricemia with the occurrence of urinary tract stones in BPH patients. Furthermore, there was no relationship between the use of antihypertensive drugs with the occurrence of urinary tract stones in BPH patients.

Antihypertensive drugs were used by BPH patients who had hypertension or with a history of hypertension. The two most commonly antihypertensive drugs used were calcium-channel blockers and angiotensinconverting enzyme inhibitors (Table 4).

The most dominant risk factor for the occurrence of urinary tract stones in $\mathrm{BPH}$ patients was diabetes mellitus. The BPH patients with diabetes mellitus had a 3-fold risk of developing urinary tract stones compared to $\mathrm{BPH}$ patients without diabetes mellitus (Odds Ratio=3.000; the Wald value was $>3.84$ and p-value <0.05; CI 95\% 1.039-8.695).

\section{Discussions}

Factors associated with the occurrence of urinary tract stones include age, race, heredity, metabolic syndrome, systemic disease, urinary tract infections, anatomical abnormalities of the urinary tract, nutritional patterns, climate, and occupation. ${ }^{4,6,7}$ Our study has shown that hypertension, obesity, hyperuricemia, and the use of antihypertension drugs are not related to the presence of urinary tract stones in $\mathrm{BPH}$ patients. Interestingly, age and diabetes mellitus are associated with the presence of urinary tract stones in BPH patients.

Hypertension as a risk factor for urinary tract stones is still controversial. A systematic review and meta-analysis study have shown that hypertension significantly increases the excretion of calcium, oxalate, and uric acid in the urine, leading to stone formation. ${ }^{11}$ Furthermore, the occurrence of hypertension can also be caused by the occurrence of kidney stones, so that there is a two-way relationship between the incidence of hypertension and urinary tract stones. ${ }^{12}$ However, a report from Germany ${ }^{13}$ revealed that there was no difference in the risk of kidney stones between patients with hypertension and patients who were not, similar to our study that shows no relationship between hypertension and urinary tract stones in BPH patients. This is probably because most hypertensive patients are currently under treatment.

The study has shown that obesity is associated with an increased risk of kidney stones, ${ }^{12}$ by excreting more calcium, oxalate, and uric acid in urine. Furthermore, increased body mass index is associated with a significantly decreased urine $\mathrm{pH}^{14,15}$ About $63 \%$ of the stones in obese people contain uric acid stones. ${ }^{15}$ However, our result shows no relationship between obesity and the presence of urinary tract stones in BPH patients. This controversial result is probably caused by the small number of obese patients in this study, which is only $38.8 \%$ of BPH patients.

The level of blood uric acid contributes to the formation of urinary tract stones. The higher levels of blood uric acid, the higher the risk of urinary tract stones. ${ }^{16}$ Hyperuricemia will reduce the $\mathrm{pH}$ in urine, which can cause uric acid stones. ${ }^{16}$ However, our result shows that there is no relationship between hyperuricemia with the presence of urinary tract stones in BPH patients. This study contradicts the previous studies, again it might be due to the small number of samples and many data were missing. In Indonesia, not all BPH patients are tested for blood 
uric acid levels routinely. A retrospective cohort study has shown that thiazide-type antihypertensive drugs can reduce the risk of urinary tract stone formation, by reducing calcium levels in the urine. ${ }^{17}$ On the contrary, another antihypertensive drug of angiotensinconverting enzyme-inhibitor (ACEI) or angiotensin receptor blocker (ARB) and calcium channel blocker (CCB) can increase the level of calcium in the urine, thus it serves as a risk to the formation of urinary tract stones. ${ }^{17}$ In our study, there was no relationship between the use of hypertension drugs with the presence of urinary tract stones. This is likely due to the length of time hypertension patients have suffered from hypertension and the duration of taking antihypertensive drugs are not recorded.

Two of the risk factors associated with the presence of urinary tract stones in BPH patients are age and diabetes mellitus. With the increasing age, the risk for urinary tract stones in BPH patients is getting higher. The peak age of urinary tract stones in this study was 60-69 years old. After the peak of its age, the risk of urinary tract stones will diminish. ${ }^{6}$ Diabetes mellitus is one of the metabolic syndromes in addition to hypertension and obesity which is the risk factor of urinary tract stones. ${ }^{18}$ Insulin resistance caused by diabetes mellitus will lead to the formation of uric acid stones of $30-40 \%{ }^{18}$ Other studies mentioned that diabetics with urinary stones have 6 times the risk of uric acid stone formation compared to people with urinary tract stones that do not have diabetes mellitus. ${ }^{19}$ The results of our study reveals that BPH patients accompanied by diabetes mellitus have a 3 -fold risk of urinary tract stones compared to BPH patients without diabetes mellitus.

This study has some limitations. The source of this study was secondary data from the registries and medical records with many missing data in the medical records, resulting in incomplete analysis of each variable used a different number of samples. The method used in this study is a retrospective design. The development of the disease could thus not be followed up and monitored. Moreover, urinary tract stones are formed due to many factors, both intrinsic and extrinsic. In this study, not all factors have been examined.

To conclude, diabetes mellitus is associated with the occurrence of urinary tract stones in $\mathrm{BPH}$ patients. The diabetes mellitus status can be used as information for conducting imaging tests routinely to identify urinary tract stones in $\mathrm{BPH}$ patients.

\section{References}

1. Lim KB. Epidemiology of clinical benign prostatic hyperplasia. Asian J Urol. 2017;4(3):148-51.

2. Nagarathnam M, Latheef SAA. Prevalence of lower urinary tract symptoms in patients of benign prostatic hyperplasia attending tertiary care hospital in the State of Andhra Pradesh. J Dr NTR Univ Health Sci. 2017;6(3):154-7.

3. Thiruchelvam N. Benign prostatic hyperplasia. Surgery (Oxford). 2014;32(6):314-22.

4. Roehrborn CG. Benign prostatic hyperplasia: etiology, pathophysiology, epidemiology, and natural history. In: Wein AJ, Kavoussi LR, Partin AW, Peters C. Campbell-Walsh urology. $11^{\text {th }}$ ed. Philadephia: Elsevier; 2016. p. 3242-88.

5. Jung JH, Park J, Kim WT, Kim HW, Kim $\mathrm{HJ}$, Hong $\mathrm{S}$, et al. The association of benign prostatic hyperplasia with lower urinary tract stones in adult men: A retrospective multicenter study. Asian J Urol. 2018;5(2):118-21.

6. Liu Y, Chen Y, Liao B, Luo D, Wang K, Li H, et al. Epidemiology of urolithiasis in Asia. Asian J Urol. 2018;5(4):205-14.

7. Aggarwal R, Srivastava A, Jain SK, Sud R, Singh R. Renal stones: a clinical review. EMJ Urol. 2017;5(1):98-103.

8. Tjahjodjati, Soebadi DM, Umbas R, Poernomo BB, Wijanarko S, Mochtar $\mathrm{CA}$, et al. Panduan penatalaksanaan klinis pembesaran prostat jinak (Benign Prostatic Hyperplasia/BPH). $3^{\text {rd }}$ ed. Jakarta: IAUI; 2017. p. 1-12.

9. Lukito AA, Harmeiwaty E, Hustrini NM, editors. Konsensus penatalaksanaan hipertensi 2019. Jakarta: Perhimpunan Dokter Hipertensi Indonesia; 2019. p. 7-8.

10. World Health Organization Regional Office for the Western Pacific. The AsiaPasific perspective: redefining obesity and its treatment. Sydney: Health Communications Australia; 2000. p. 17.

11. Besiroglu H, Otunctemur A, Ozbek E. The metabolic syndrome and urolithiasis: a systematic review and meta-analysis. Ren Fail. 2015;37(1):1-6.

12. Boyd C, Wood K, Whitaker D, Assimos DG. The influence of metabolic syndrome and its components on the development of nephrolithiasis. Asian J Urol. 2018;5(4):215-22.

13. Pfau A, Knauf F. Update on nephrolithiasis: core curriculum 2016. Am J Kidney Dis. 
2016;68(6):973-85.

14. Trinchieri A, Croppi E, Montanari E. Obesity and urolithiasis: evidence of regional influences. Urolithiasis. 2017;45(3):271-8.

15. Aydogdu O. Urinary stone disease and obesity: different pathologies sharing common biochemical mechanisms. World J Nephrol. 2012;1(1):12-5.

16. Lim D-H, Kim M, Hong S, Kim Y-G, Lee $\mathrm{C}-\mathrm{K}$, Choi SW, et al. Is the serum uric acid level independently associated with incidental urolithiasis? J Rheum Dis. 2018;25(2):116-21.
17. Alexander RT, McArthur E, Jandoc R, WelkB, Hayward JS, Jain AK, et al. Antihypertensive medications and the risk of kidney stones in older adults: a retrospective cohort study. Hypertens Res. 2017;40(9):837-42.

18. Wong Y V, Cook P, Somani BK. The association of metabolic syndrome and urolithiasis. Int J Endocrinol. 2015;2015:1-9.

19. Abou-Elela A. Epidemiology, pathophysiology, and management of uric acid urolithiasis: a narrative review. J Adv Res. 2017;8(5):513-27. 